\title{
Feminização do magistério e masculinização do comando educacional: estudos no Teachers College da Universidade de Columbia (1927-1935)
}

\section{Feminization of school teaching and masculinization of educational command: studies at Teachers College, Columbia University (1927-1935)}

\author{
Mirian Jorge Warde* \\ Ana Cristina Santos Matos Rocha**
}

\begin{abstract}
RESUMO
Embora o professorado tenha se feminizado a partir de meados do século XIX - em praticamente todos os países ocidentais - os postos mais altos da administração e a condução intelectual da instrução pública permaneceram dominantemente masculinos. Neste artigo, fazemos, preliminarmente, uma breve aproximação à historiografia que nos informa sobre os processos de feminização do magistério primário nos Estados Unidos e no Brasil. Em seguida, colocamos o foco no Teachers College da Universidade de Columbia, instituição que, criada com foco na mulher, passa em curto tempo ao controle masculino. Por fim, apresentamos casos de brasileiros e brasileiras que estudaram no Teachers College entre as décadas de 1920 e 1930 . Esses expressam, em suas trajetórias, as condições desiguais de profissionalização e ascensão na carreira.
\end{abstract}

Palavras-chave: Teachers College. Universidade de Columbia. Feminização do magistério. Intelectuais da educação. Viagens de estudo.

* Universidade Federal de São Paulo. Programa de Pós-Graduação em Educação. Guarulhos, São Paulo, Brasil. E-mail: mjwarde@uol.com.br. https://orcid.org/0000-0002-1119-6729

** Fundação Oswaldo Cruz. Programa de Pós-Graduação em História das Ciências e da Saúde. Rio de Janeiro, Rio de Janeiro, Brasil. E-mail: anasmrocha@gmail.com. https://orcid. org/0000-0001-5718-1293 


\begin{abstract}
Although the school teaching became feminized from the middle of the 19th century onwards - in practically all Western countries - the highest administration posts and the intellectual conduction of public instruction remained predominantly masculine. In this article, first we briefly approach the historiography that informs us about the feminization processes of primary teaching in the United States and Brazil. Next, we focus on Teachers College at Columbia University, an institution that was initially created with a focus on women and, passed, in short time, to male control. Finally, we present cases of Brazilian women and men who studied at Teachers College between the 1920s and 1930s and who, in their trajectories, express the unequal conditions of professionalization and career advancement.
\end{abstract}

Keywords: Teachers College. Columbia University. Feminization of school teaching. Education intellectuals. Academic travels.

\title{
Introdução
}

A historiografia disponível indica que o processo de feminização do magistério ocorreu em torno da mesma época em países ocidentais, europeus e americanos, ainda que o ritmo de crescimento e a extensão dos sistemas públicos de ensino tenham sido distintos. Na quase totalidade dos casos, as referências dizem respeito ao ensino primário, entre meados do século XIX e as primeiras décadas do século $\mathrm{XX}^{1}$. Por outro lado, as causas ou as razões alegadas para a presença crescente das mulheres nas escolas elementares não convergem necessariamente, nem estão firmemente estabelecidas; ou melhor, os historiadores de diferentes ramos não estabeleceram um consenso - ao menos até o momento - a respeito dos fatores que teriam levado a esse processo que tem sido chamado de feminização do magistério².

Neste artigo, apresentaremos, inicialmente, um breve balanço em torno do assunto. Merece atenção a escassez de estudos com destaque ao processo

1 Talvez a exceção mais impressionante seja da Alemanha. Albisetti (1993) apresenta um estudo comparado da feminização do magistério no século XIX no qual se destaca a diferença para muito menos entre aquele país e outros países da Europa e da América do Norte. A entrada massiva de mulheres no magistério alemão teria ocorrido a partir da segunda década do século XX.

2 Yannoulas (1993, p. 718) reserva o termo "feminilização" para o processo de dominância quantitativa das mulheres e "feminização" para os aspectos qualitativos daquele processo, ou seja, "a feminização propriamente dita”. Embora seja acertada a distinção, não utilizamos essa nomenclatura no texto na expectativa de termos mais adequados. 
de masculinização da direção política e intelectual do campo educacional, concomitante ao processo de feminização do magistério. Os Estados Unidos representam uma significativa exceção (STROBER; TYACK, 1980). Aqui, o uso do termo "masculinização" não é correlato ao de "feminização"; neste caso, os estudos apontam os processos que levaram à prevalência da presença feminina em postos antes exclusivos ou dominantemente ocupados por homens ${ }^{3}$. No caso da referida "masculinização", não se trata, certamente, de processo equivalente com sinais invertidos: não havia mulheres no comando educacional que tenham sido substituídas por homens; porém, esse é um bom termo para salientar o contraste entre a entrada massiva das mulheres em sala de aula e a sua ausência, ou pequena presença, no comando do campo. No tópico seguinte, apresentamos o Teachers College da Universidade de Columbia (TC) à luz desse contraste, aliás, ponto de vista pouco considerado nos estudos sobre esse College: o da hegemonia masculina. Na última parte, examinamos as experiências de alguns educadores brasileiros que foram ao Teachers College, ressaltando o papel que a especialização desempenhou em suas trajetórias.

\section{Feminização do magistério e os postos/cargos de direção: Estados Unidos e Brasil}

A historiografia estadunidense consensualmente estabelece, em meados do século XIX, o início do crescimento vertiginoso das mulheres no magistério elementar. Por um lado, a constituição de sistemas públicos de ensino e o aumento crescente de crianças imigrantes nas escolas pressionavam pelo aumento de salas de aula e turnos escolares; por outro, a urbanização e a industrialização, com ofertas de novos empregos mais bem remunerados para os homens, são fatores destacados para explicar o processo de entrada massiva da mulher na docência primária, embora as diferentes vertentes dos estudos feministas tenham divergências a respeito (SCHMUCK, 1987; CLIFFORD, 1989).

A feminização, no sentido de aumento do contingente feminino nas escolas, não implicou a concomitante feminização do trabalho escolar. A prova mais

3 Faria Filho e Macedo (2004, p. 2), examinando a feminização do magistério em Minas Gerais (1860-1910), advertem que "é preciso considerar também que, ao que tudo indica, a maioria dos homens que entraram para o magistério nas décadas finais do século XIX não deixou o magistério. $\mathrm{O}$ fato de os homens terem deixado de entrar não é a mesma coisa que dizer que eles saíram. Afirmar isto significa que, talvez, devamos pesquisar as causas da desmasculinização do magistério tanto em razões externas à escola e ao aparelho escolar quanto no próprio incremento do processo de escolarização e nas transformações pelas quais passava a própria instituição escolar". 
contundente, oferecida pela historiografia feminista, é o aumento do número de mulheres nos postos administrativos dentro e acima das escolas, bem como do número de autoras publicadas nas três primeiras décadas do século XX, seguido de declínio nos anos subsequentes. Ou seja, a presença maior de mulheres em postos de direção teria sido conjuntural e não teria representado o controle feminino do campo educacional. Outra prova identicamente contundente se refere ao controle masculino do campo acadêmico que muito recentemente havia incorporado os estudos educacionais nas universidades, mantendo-se sobre eles a imagem de "estudos menores" ou "coisas de mulher". Falaremos a respeito no próximo tópico.

No caso do Brasil, na quase totalidade das regiões, deu-se também a feminização do magistério como processo de crescimento do professorado feminino em relação ao masculino na escola elementar, a partir das últimas décadas do século XIX. A maioria dos postos de comando e a condução intelectual do campo educacional em formação permaneceram fortemente masculinos. As mulheres que ocuparam lugares de direção escolar ou de autoria foram, em regra, chanceladas por homens em um terreno configurado masculinamente. Nas escolas normais, ponto alto da formação docente até os anos de 1930, as cadeiras continuaram concentradas em mãos masculinas.

Como dizem Gondra e Schueler (2008), homens legislavam sobre a instrução pública e comandavam os procedimentos de recrutamento e seleção docentes nos seus diferentes níveis. As oportunidades profissionais que as viagens de estudos ensejaram para as brasileiras que se especializaram no TC -e os cargos que ocuparam após o regresso - sugerem trajetórias equivalentes às realizadas pelas professoras daquela faculdade: número maior de vagas disponíveis para mulheres e maiores chances de ascensão feminina na carreira, mas seus horizontes de possibilidades eram demarcados pelos homens. O comando do campo permanecia monopólio masculino.

\section{O Teachers College da Universidade de Columbia: entre "duas esferas"}

Historiadores estadunidenses, como Cremin, Shannon e Towsend (1954), concordam com Toopfer (1966, s. p.) que afirma um papel de liderança do Teachers College da Universidade de Columbia "ao transformar a educação pública e o treinamento profissional de professores ocorridos nos Estados Unidos na primeira metade do século XX”. Muito da força adquirida pelo College, 
segundo o autor, teria sido adquirida nos primeiros tempos, entre 1897 e 1915, sob a liderança do Dean James E. Russell.

A iniciativa de criação do Teachers College foi de Grace Dodge, filantropista, herdeira de vastíssima fortuna; o seu alvo era ampliar as alternativas de qualificação profissional feminina (KATZ, 1980). Logo, porém, os alvos de Dodge foram substituídos pela ênfase na formação profissional de docentes, adotada pelo primeiro presidente do Teachers College, Nicholas Murray Butler que assumiu, posteriormente, a presidência da Universidade. Com isso, Butler teria conseguido - com muito esforço - tornar o College em uma instituição "afiliada" da Universidade de Columbia (TOEPFER, 1966; KATZ, 1980).

Segundo relato de Russell (1900a), o TC, fundado em 1888, tornou-se parte do sistema educacional da Universidade de Columbia em $1889^{4}$. A administração do College ficou sob responsabilidade do seu próprio Conselho de Curadores, com 18 membros, sendo que o Presidente da Universidade foi o presidente ex officio do TC. O College, assim, ao entrar para a Universidade, manteve sua própria existência corporativa enquanto submetia o controle educacional geral às autoridades universitárias. O diretor executivo do College era o Dean, eleito pelos Curadores e nomeado pelo Presidente da Universidade. Os professores respondiam pela chefia dos departamentos no College e supervisionavam o ensino em suas respectivas disciplinas nas escolas de observação e prática. Russell (1900a) se refere a sete membros operacionais do corpo administrativo, sendo cinco homens e duas mulheres; uma, a diretora da Horace Mann Elementary School; a outra, a escriturária. Quanto ao corpo docente, são citados dezesseis professores e quatro mulheres, responsáveis pela Domestic Science, Domestic Art, Kindergarten e Physical Training, além de 22 instrutores e assistentes, não discriminados.

Russell (1900a) se refere, ainda, a duas escolas de observação e prática mantidas pelo TC: a Horace Mann School e a conhecida como a Experimental School. A Horace Mann School é uma escola paga para crianças dos dois sexos que pretendem obter uma educação secundária completa. A Experimental School, também para os dois sexos, oferece matrícula gratuita para crianças da vizinhança que não podiam continuar seus estudos além dos graus elementares. Ambas as escolas funcionariam como um grande laboratório de trabalho em todas as linhas de formação profissional e pesquisa fornecidas pelo $\mathrm{TC}^{5}$.

4 Cremin, Shannon e Towsend (1954, p. 31) datam no ano acadêmico 1892-1893: "a primeira aliança formal com o College de Columbia".

5 Essas escolas cobrem do kindergarten ao high school, ou seja, os níveis anteriores ao superior. Não confundir, portanto, com as "escolas" sobre as quais falaremos adiante que organizavam os estudos superiores do TC, em nível de graduação e pós-graduação. 
Em outro relatório do mesmo ano, Russell (1900b) descreve a organização dos estudos no TC em três grupos: a) Cursos de pós-graduação que, projetados para qualificação profissional avançada e também para promover pesquisa e investigação no campo da educação, conferem os mais altos diplomas do College: um curso para professores de escolas normais, para diretores, supervisores e superintendentes de escolas e um curso para professores de escolas secundárias e instrutores de faculdades; b) Cursos gerais de graduação: um curso para professores nas escolas primárias; um curso para professores do jardim de infância e c) outros cursos para professores e supervisores de áreas específicas.

Mudanças significativas nessa estrutura foram introduzidas entre 1900 e 1915, tanto no âmbito administrativo quanto no acadêmico do TC. As exigências para ingresso se tornaram muito mais rígidas, os critérios para acesso aos títulos mais altos se tornaram mais duros, e a separação entre os cursos de estudo (carreiras) se tornaram mais firmes.

Cremin, Shannon e Towsend (1954) destacam, entre as mais importantes mudanças introduzidas após aquela estruturação de 1900, a criação, em 1902, de cinco departamentos decorrentes da redistribuição da Divisão de Educação Geral: História e Filosofia da Educação, Administração Educacional, Psicologia Educacional, Educação Elementar e Educação Secundária; e, em 1910, a reunião de todos os cursos técnicos e práticos na School of Industrial Arts (Escola de Artes Industriais) e na School of Household Arts (Escola de Artes Domésticas).

A partir dessas mudanças, outra ainda mais decisiva foi introduzida com a criação, em 1912, da School of Practical Arts (Escola das Artes Práticas), que integrava a School of Industrial Arts e a School of Household Arts, e se separava da School of Education (Escola de Educação). Para Cremin, Shannon e Towsend (1954, p. 62), seguindo a posição dos dirigentes do TC, essa reorganização mais drástica teria decorrido não só pela demanda constante de treinamento prático, mas também pela persistente preocupação do Dean em acolher as mulheres no campo da ciência doméstica, fornecendo-lhes "sólida base científica". Havia procura pela ciência doméstica e o College pretendia preservar sua liderança no fornecimento de treinamento mais amplo e mais substantivo nessa área.

Com isso, a School of Education ficou com inteiro controle dos estudos que conduziam ao título de Bachelor of Science, além de vários outros diplomas em educação, enquanto a School of Practical Arts conferia o diploma de bacharel em artes práticas. Assim como as demais faculdades da Universidade de Columbia, essa separação tendeu a segregar os estudantes de graduação, ou a maioria deles, na School of Practical Arts. Como veremos adiante, essa segregação recaiu basicamente sobre as mulheres.

Entusiasmado com o aumento da procura, ainda em 1912, o Dean Russell propôs elevação das exigências de ingresso no College e a dedicação da 
School of Education aos cursos de pós-graduação, de modo a garantir para o TC a capacidade de seleção e sua crescente liderança nacional e internacional ${ }^{6}$ (CREMIN; SHANNON; TOWSEND, 1954).

Nos anos da guerra mundial e nos que a sucederam, o TC - como a Columbia em geral - diversificou suas frentes de atuação, chancelando sua vocação para a intervenção nos rumos nacionais e internacionais. Por um lado, iniciativas de alcance imediato; de outro, iniciativas acadêmicas que levaram mais longe a separação interna entre as suas escolas. Em 1916, criou o Department of Educational Research, com elevadas exigências para obtenção dos títulos de mestrado (M. A.) e de doutorado (Ph. D.). Nos anos ditos de "reconstrução pós-guerra", a principal iniciativa na linha de extensão do raio de atuação do TC foi a criação do International Institute, em 1923, que acolheu estudantes de todos os continentes em programas especiais (BU, 1997).

Os estudos feministas projetaram outras perspectivas de análise aos processos de (re)organização constante do TC desde 1900. Onde Cremin e coautores viram acerto nas escolhas dos dirigentes, rumo à edificação de um College de elevada reputação nacional e internacional, epicentro de diferentes processos de configuração do campo educacional em âmbito global, Thomas (1986) e, posteriormente, Weneck (1996) viram as mulheres - alvo prioritário quando da criação da Instituição - serem represadas nas carreiras de menor destaque e, principalmente, com potenciais de poder e de direção intelectual bem mais reduzidos.

Estudando o período de 1913 a 1933, Thomas (1986) identificou a separação do TC em duas esferas: a masculina e a feminina. Naqueles vinte anos, o TC teria criado uma separação eficaz entre a School of Practical Arts, que oferecia formação profissional em nível de graduação e concentrava um número muito superior de mulheres tanto como alunas quanto como docentes. A School of Education, reservada a partir de meados da década de 1910 aos estudos pós-graduados, tornou-se província dos homens. O elevado prestígio e status usufruído pelo TC ficaram concentrados em umas tantas figuras masculinas, cujos nomes se projetaram em âmbito internacional.

No período examinado, Thomas (1986) constatou que, embora no TC as mulheres constituíssem a maioria discente e docente, os maiores recursos, salários e carreiras ficaram desequilibradamente concentrados nos postos

6 Russell fala de um crescimento de 1.300 por cento desde 1897. "A matrícula no ano passado mostra que nossos estudantes vieram de 47 estados e territórios e 17 países estrangeiros. $\mathrm{O}$ treinamento anterior foi realizado em 186 faculdades e universidades, 116 escolas de norma e 96 outras instituições de um ranking acima da escola secundária”. Para esses dados e análises, Cremin, Shannon e Towsend (1954, p. 64.) se basearam num Confidential Report of the Dean datado de 1912. 
administrativos e de pesquisa ocupados pelos homens. Com isso, o TC teria contribuído eficazmente para a difusão da representação de efeito prolongado dentro e fora dos Estados Unidos pela qual as mulheres foram incorporadas à educação em igualdade de condições, por isso, teriam suas condições profissionais igualadas às dos homens.

No caso do International Institute, toda a direção do programa ficava a cargo dos homens: Paul Monroe (diretor), Isaac Kandel e William Russel (ambos diretores associados). As disciplinas ministradas para alunos estrangeiros também eram, em sua maioria, dirigidas e ministradas por homens, à exceção dos cursos de inglês para estrangeiros (Miss. Diller) e Rural and Village Education - cujas professoras responsáveis eram Mabel Carney e Fannie Dunn (INTERNATIONAL INSTITUTE, 1923).

Os estudos de educação rural eram considerados pelos professores do Instituto como estratégico para os estudantes que vinham de países considerados, por eles, como atrasados. Em teoria, o debate lhes forneceria conselhos úteis ao desenvolvimento de projetos para seus países de origem. No entanto, quando a Carnegie estudava quais projetos do Teachers College mereciam financiamento em 1933, um ano classificado por eles como "particularmente difícil", William Russel preferiu "não se posicionar em relação ao projeto de Carney". Em contrapartida, afirmou que "não questionava a importância do movimento de educação rural, mas achava que ele ficava com as pessoas de menor qualidade" (FPK and Dean WM F. Russell, 31/10/1933) 7 . Não é preciso dizer que o financiamento foi recusado.

\section{As viagens ao Teachers College: especializações e perspectivas de inserção profissional no Brasil}

No Brasil, o programa promovido pelo Instituto Internacional do Teachers College de Columbia oferecia aos educadores uma oportunidade de especialização que lhes concederia espaço privilegiado no campo educacional. No entanto, suas credenciais não funcionavam isoladamente: às especializações era necessário somar as alianças feitas durante suas trajetórias profissionais, essenciais para consolidação de um lugar de atuação dentro do sistema educacional.

As viagens que esses educadores fizeram aos Estados Unidos foram financiadas tanto pelos governos estaduais, que tinham interesse em qualificar os

7 "poorest quality people", no original. 
educadores que exerceriam funções chave nos planos de reforma do seu sistema educacional, quanto por agências norte-americanas privadas, como a Carnegie Endowment. Além disso, três brasileiros puderam contar com bolsas do Macy Student Fund para estudar no Teachers College da Universidade de Columbia: Anísio Teixeira, Ignácia Guimarães e Noemy Silveira Rudolfer.

Dentre as viagens feitas em grupo, podemos citar: a viagem feita pelas educadoras mineiras, que foram enviadas por Francisco Campos e escolhidas por Ignácia Guimarães - esta convidada por Isaac Kandel para se especializar no TC como bolsista Macy (FONSECA, 2010); a que foi promovida pela Associação Brasileira de Educação (ABE) e patrocinada pela Carnegie Endowment, quando dez educadores passaram cinco semanas no país; e, por último, a viagem de Carneiro Leão, Lourenço Filho e Delgado de Carvalho, que foram enviados por Anísio Teixeira para observar aspectos do ensino norte-americano que se relacionavam com as posições profissionais que já ocupavam em sua administração.

Assim, Benedicta Valladares Ribeiro, Lúcia Schimidt Monteiro de Castro (que depois de casada tornou-se Lúcia Casasanta), Amélia de Castro Monteiro e Alda Lodi viajaram em setembro de 1927, acompanhadas de Ignácia Guimarães. Antes da partida, as três primeiras trabalhavam em Grupos Escolares da capital, enquanto Lodi trabalhava como professora das classes anexas da Escola Normal. Até fevereiro de 1929, elas cursaram disciplinas no TC e procuraram se qualificar para a tarefa que lhes esperava: trabalhar na Escola de Aperfeiçoamento de Belo Horizonte, criada por Francisco Campos, e que começou a funcionar quando elas retornaram ao Brasil (PEIXOTO, 2003). Já Ignácia Guimarães concluiu o mestrado no TC e seguiu para Alemanha, onde permaneceu até setembro de 1929.

A "delegação brasileira" da ABE foi enviada para o curso de aperfeiçoamento promovido em parceria com a Carnegie em janeiro de 1930. Por fim, o trio que viajou em janeiro de 1935, enviado por Anísio Teixeira, já ocupava espaços estratégicos no campo educacional. Lourenço Filho, então diretor do Instituto de Educação, deveria observar as Escolas Normais e os Teachers Colleges norte-americanos. Já Delgado de Carvalho, então diretor do Instituto de Pesquisas Educacionais do Distrito Federal (MACEDO, 2013), se concentraria nos Institutos de Pesquisa, enquanto Carneiro Leão deveria observar as atividades de supervisão e administração do sistema de educação daquele país, o que lhe ajudaria a pensar as aulas que ministrava na Escola de Professores do Instituto de Educação (CPDOC, AT c 1927.02.16). Eles passaram três meses nos Estados Unidos, entre Nova Iorque, Washington D.C., Filadélfia e Baltimore (CPDOC, AT c 1929.11.01).

Todos esses educadores passaram pelo TC, ainda que nem todos tenham se dedicado exclusivamente aos estudos nessa faculdade. A maior parte deles teve suas viagens divulgadas pelos jornais, numa narrativa que exaltava o fato 
de que esses educadores se qualificavam em áreas específicas de atuação no ensino, o que apontava a crescente profissionalização do campo. Nesse sentido, a experiência de viagem credenciava tanto os educadores (GONDRA, 2010) quanto as administrações que os enviavam, já que sinalizavam o compromisso que tinham com a formação de seus quadros.

De todo modo, é preciso estar atento às redes que sustentaram algumas das indicações que possibilitaram essas viagens. Como nos alerta Silmara Cardoso (2015), no caso da missão da $\mathrm{ABE}$, todos os educadores que integraram a viagem eram filiados à Associação, à exceção das professoras indicadas pelo prefeito de São Paulo. A maior parte deles ocupou cargos estratégicos na instituição: Laura Lacombe, Octávio Barbosa do Couto e Silva, Othon Leonardos e Décio Lyra da Silva eram parte do Conselho Diretor eleito em outubro de 1929. No ano seguinte, depois da viagem, Consuelo Pinheiro fará parte desse mesmo Conselho (CARVALHO, 1998, p. 486-488).

Já no caso da viagem das educadoras enviadas por Francisco Campos, pelo menos duas delas participavam dos círculos das elites políticas mineiras: Benedicta Valladares era filha de Antonio Benedicto Valladares Ribeiro, senador, que participou da Comissão Geral de Ensino (ARAUJO, 2010); e Lúcia de Castro era prima de Cristiano Machado, prefeito de Belo Horizonte (MACIEL, 2001). Já o caso de Alda Lodi é menos direto: ao estudar sua trajetória, Nelma Fonseca (2010) destaca as correspondências que nos deixam inferir a relação que sua família manteve com Arthur Bernardes.

Ao contrário da missão da $\mathrm{ABE}$, que exigia como contrapartida apenas a elaboração de um relatório, o grupo enviado por Francisco Campos teve sua viagem associada ao projeto de reforma do ensino de Minas Gerais. Assim, dois fatores devem ser considerados em suas trajetórias profissionais: o primeiro é o fato de que essas educadoras já tinham um lugar à sua espera quando retornaram, e o segundo é que suas viagens estão diretamente ligadas à sua ascensão profissional. Nesse sentido, a trajetória de Ignácia Guimarães é interessante justamente porque, apesar de integrar o grupo, ela ocupa uma posição diferente nesse contexto.

A princípio, Guimarães teria maiores possibilidades de ascensão profissional tanto pela sua formação quanto pelas circunstâncias de sua viagem, uma vez que a ela foi concedida uma bolsa do Macy Student Fund. Assim, sua partida estava tanto vinculada ao projeto de internacionalização do Teachers College, com bolsa concedida por Isaac Kandel, quanto à administração de Francisco Campos, que lhe concedeu a licença. No entanto, ao que parece, é justamente o fato de sua viagem não estar diretamente vinculada ao projeto de renovação comandado por Campos que lhe fez voltar à sua antiga cadeira na Escola Normal Modelo. Sem esse vínculo, Guimarães precisou construir sua 
ascensão profissional a partir de outras alianças, como a que fará mais tarde com Anísio Teixeira.

É certo que as viagens foram um elemento importante na carreira de educadoras como Maria dos Reis Campos e Noemy Silveira Rudolfer, que passaram a integrar a viagem graças à desistência de dois membros da delegação inicial: Maria da Conceição Junqueira e Gustavo Lessa (Arquivo da ABE. Intercâmbio intelectual - Correspondências). Maria dos Reis Campos, na época da viagem, era inspetora escolar do Distrito Federal, especializou-se no método de projetos. Em 1933, é ela quem irá liderar a Seção de Programas do Ensino Secundário do Instituto de Educação (PINTO, 2004).

Já Noemy Silveira Rudolfer, a partir da viagem da ABE, foi indicada para a bolsa do Macy Student Fund por Paul Monroe. Durante o semestre que cursou no Teachers College, Rudolfer aprofundou seus conhecimentos em psicologia educacional, área em que atuou durante grande parte da sua trajetória profissional. Quando voltou, em fevereiro de 1931, Rudolfer assumiu a chefia do Serviço de Psicologia Aplicada (SPA) do Departamento de Educação paulista, onde deveria usar os conhecimentos adquiridos na viagem, aliado à experiência que já possuía como auxiliar de Lourenço Filho no Laboratório de Psicologia da Escola Normal. Depois, continuou seu trabalho como professora de psicologia educacional na USP. Sua indicação ao SPA foi sustentada por Lourenço Filho, que estava à frente da Diretoria Geral de Instrução Pública do Estado.

O caso das professoras enviadas por Francisco Campos é também um bom exemplo dessa ascensão. Quando retornaram de viagem, Amélia de Castro Monteiro, Alda Lodi e Lúcia Casasanta deixaram os postos que ocupavam para trabalhar na recém-criada Escola de Aperfeiçoamento, como previa o plano de Francisco Campos. Ignácia Guimarães, em carta para Anísio Teixeira, afirmava que Amélia e Lúcia eram "as diretoras de fato do curso, pois o diretor oficial é professor de uma das cadeiras da Escola de Minas de Ouro Preto e, por isso, não tem tempo o bastante para dirigi-lo" (CPDOC, AT c 1929.07.23/2, doc. 3). Nesse trecho, Guimarães se referia a Lúcio dos Santos, o primeiro diretor da Escola (A INSTALLAÇÃO..., 1929, p. 7), que era um dos elementos chave na reforma de educação feita por Campos em Minas Gerais.

Da "missão mineira", Benedicta Valladares Ribeiro foi a única educadora escolhida pelo próprio Francisco Campos para integrar o grupo (ARAUJO, 2010; FONSECA, 2010). Antes da viagem, ela trabalhava como professora do Grupo Escolar Henrique Diniz. Depois, trabalhou na orientação do curso profissional da Escola Normal Modelo, onde havia se formado em 1922. Ribeiro havia cursado diversas disciplinas ligadas à prática de ensino no Teachers College (ARAÚJO, 2010), o que poderia justificar a posição que passou a ocupar em seu retorno. No entanto, a rede política que sustentou sua indicação para a 
viagem de estudos foi apontada por Guimarães como um dos fatores que influenciaram o prestígio que ela e sua irmã desfrutavam nesta Escola (CPDOC, AT c 1929.07.23/2, p. 11).

Quando retornou a Belo Horizonte, em setembro de 1929, Ignácia Guimarães foi nomeada assistente técnica do ensino normal (CPDOC, AT c 1929.07.23/2, p. 11). Apesar do diploma de mestrado do Teachers College, voltou a ocupar a cadeira de metodologia na Escola Normal Modelo (CPDOC, AT c 1929.07.23/2, p. 14). Em 1924, depois de sua primeira viagem de estudos no Peabody College for Teachers, Guimarães havia sido professora nesta mesma instituição (MINAS..., 1929, p. 1; BARBOSA, 2015).

Durante sua trajetória, Ignácia nem sempre teve uma boa relação com as posições que ocupou. Cardoso (2014), ao explorar as cartas da educadora enviadas para Anísio Teixeira, nos dá uma pista do quanto ela aprendeu e procurou refletir sobre as experiências que teve na Alemanha e nos Estados Unidos, assim como o prestígio que obteve em função dessas viagens. No entanto, suas cartas também sinalizam as dificuldades de Guimarães que, de acordo com ela mesma, ficava "à disposição da secretaria de educação, onde 'nada há' para fazer" (CPDOC, AT c 1929.07.23/2, p. 31).

Outra pista é a carta que escreveu para Anísio Teixeira em setembro de 1933 (CPDOC, AT c 1929.07.23/2, p. 30; CARDOSO, 2014). Nela, Guimarães, que atuava como chefe do Serviço de Programas Escolares do Instituto de Educação desde 1932, lamenta ter perdido o posto para Maria dos Reis Campos, a quem agora deveria se reportar em sua nova designação: "professora encarregada das atividades extra-classe". A posição que passou a ocupar era por ela considerada "inaceitável”. Sua experiência de estudos no TC, onde foi colega de Anísio Teixeira, era ali lembrada para mostrar sua qualificação.

Na mesma carta, oferece ao amigo a solução: que fosse subordinada a Delgado de Carvalho, uma vez que, com a reforma, ele passara a assumir o Instituto de Pesquisas Educacionais. Nos limites da pesquisa feita para este artigo, não sabemos qual foi a decisão tomada por Anísio Teixeira. De todo modo, em 1936, Guimarães aparece como chefe da Seção de Programas e Atividades Extraclasse do Instituto de Pesquisas Educacionais, que nessa época já estava sob a direção de Lourenço Filho (MACEDO, 2013). Ainda que a carta a Anísio Teixeira sinalize, como afirma Cardoso (2014, p. 251), que Guimarães "se reconhece como alguém de autoridade para interferir sobre o lugar e a posição que deveria ocupar", é preciso considerar que ela ainda possuía pouca autonomia dentro do campo educacional, o que demonstra a necessidade de considerar outros fatores para analisar a ascensão feminina, além da qualificação profissional.

Enquanto, para essas mulheres, a viagem de estudos aos Estados Unidos e suas especializações eram parte do discurso que justificava a posição que 
ocupavam no campo educacional, o mesmo não pode ser dito sobre a viagem de outros educadores. No caso de Delgado de Carvalho, Lourenço Filho e Carneiro Leão, por exemplo, a lógica parece ser contrária: é justamente o lugar que ocupam no campo que os credenciam para que viagem em 1935, em missão oficial pela Diretoria de Instrução Pública do Distrito Federal.

Tanto Delgado de Carvalho quanto Carneiro Leão já conheciam os Estados Unidos, e Lourenço Filho já tinha feito uma viagem à Europa. Além disso, Carneiro Leão e Lourenço Filho já tinham trabalhado como diretores de instrução pública: o primeiro, no Rio de Janeiro e em Pernambuco; o segundo em São Paulo e no Ceará. Por isso, cabe ressaltar que os três meses que passaram nos Estados Unidos tinham como finalidade a reflexão sobre um aspecto específico da política educacional, mais do que a qualificação para o ensino.

Havia também os que não tinham suas práticas profissionais diretamente ligadas ao campo da educação elementar ou da formação de professores, como Octávio Barbosa do Couto e Silva e Othon Leonardos. Ambos eram sócios da ABE e participavam dos debates no campo da educação, mas atuavam no ensino superior, em cursos de bacharelado da Faculdade de Medicina e da Escola Politécnica, respectivamente. Couto e Silva já havia inclusive recebido bolsa da Fundação Rockefeller para estudar na Universidade de Chicago entre 1927 e 1928 (Arquivo da ABE, Intercâmbio intelectual - Correspondências). A área que escolheram como foco na missão da $\mathrm{ABE}$, "organização universitária", também tem relação com essa diferença.

\section{Considerações finais}

Cabe pensar nos espaços de formação frequentados por esses educadores antes de suas viagens e nas redes intelectuais que se formavam a partir daí. Enquanto as mulheres eram formadas pelas Escolas Normais, a maior parte dos homens era oriunda do ensino superior. Ainda que muitos deles tenham atuado como professores, eles o faziam nas escolas de formação e poucos tinham experiência no ensino elementar. Em contrapartida, eram as viagens de estudo que serviam como instância de validação dos conhecimentos que essas mulheres já desenvolviam aqui, como mostra a trajetória de Noemy Silveira Rudolfer, ou de especialização em uma área específica do ensino, como sinaliza a trajetória das professoras mineiras que aqui analisamos.

Interessa também pensar se e como a visita a um ambiente acadêmico sob controle de homens teria afetado as representações dos brasileiros e brasileiras 
que estagiaram no Teachers College da Universidade de Columbia a respeito do caráter democrático das relações sociais e culturais vigentes nos Estados Unidos. Eles partiram para os estágios com a expectativa de acesso a conhecimentos científicos avançados, práticas pedagógicas inovadoras e renovadoras, pois carregavam a imagem de que os Estados Unidos estariam realizando, especialmente no campo educacional, experimentos mais arrojados em termos de igualdade social. Que alguns deles tenham se chocado com a discriminação aos negros e tenham feito registros a respeito isso é sabido. Mas teriam percebido, em algum nível, a subserviência feminina particularmente no campo acadêmico?

\section{REFERÊNCIAS}

A INSTALLAÇÃO da escola de aperfeiçoamento de Minas Geraes. O Jornal, Rio de Janeiro, edição 03172, página 7, 27 mar. 1929.

ALBISETTI, J. C. The feminization of teaching in the nineteenth century: a comparative perspective. History of Education, v. 22, n. 3, p. 253-263, 1993.

ARAUJO, R. Benedicta Valladares Ribeiro (1905-1989): formação e atuação. 2010. Tese (Doutorado em Artes) - Escola de Comunicação e Artes, Universidade de São Paulo, São Paulo, 2010.

ASSOCIAÇÃO BRASILEIRA DE EDUCAÇÃO (ABE). Arquivo. Intercâmbio cultural. Intercâmbio intelectual com os Estados Unidos - Correspondências.

BARBOSA, A. M. Redesenhando o desenho: educadores, política e história. São Paulo: Cortez, 2015.

BU, L. International activism and comparative education: pioneering efforts of the International Institute of Teachers College, Columbia University. Comparative Education Review, v. 41, n. 4, p. 413-434, nov. 1997.

CARDOSO, S. "Viajar é ser autor de muitas histórias": experiências de formação e narrativas educacionais de professores brasileiros em viagens aos Estados Unidos (19291935). 2015. Tese (Doutorado em educação) - Faculdade de Educação, Universidade de São Paulo, São Paulo, 2015.

CARDOSO, S. Narrativas e representações de um percurso educacional e de um ideário educativo estrangeiro nas cartas de uma educadora. Revista HISTEDBR On-line, Campinas, n. 60, p. 246-259, dez. 2014.

CARVALHO, M. Molde Nacional e Forma Cívica: higiene, moral e trabalho no projeto da Associação Brasileira de Educação (1924-1931). Bragança Paulista: Edusf, 1998. 
CLIFFORD, G. J. Man/woman/teacher: gender, family, career in American education a history. In: WARREN, D. (Org.). American Teachers: Histories of a Profession at Work. New York: American Educational Research Association, 1989.

COLUMBIA RARE BOOK \& MANUSCRIPT LIBRARY. Carnegie Corporation New York Records. Box 114. Folder. Teachers College 1920-1935. FPK and Dean WM F. Russel. 31/10/1933.

CPDOC. Arquivo Anísio Teixeira. Correspondência entre Anísio Teixeira e Antonio Carneiro Leão. AT c 1927.02.16.

CPDOC. Arquivo Anísio Teixeira. Correspondência entre Anísio Teixeira e Inácia Guimarães sobre assuntos variados. AT c 1929.07.23/2.

CPDOC. Arquivo Anísio Teixeira. Correspondência entre Anisio Teixeira e Manoel Bergström Lourenço Filho. AT c 1929.11.01.

CREMIN, L. A.; SHANNON, D. A.; TOWSEND, M. E. A History of Teachers College, Columbia University. New York: Columbia University Press, 1954.

FARIA FILHO, L. M. de; MACEDO, E. F. P. A feminização do magistério em Minas Gerais (1860-1910): política, legislação e dados estatísticos. In: CONGRESSO BRASILEIRO DE HISTÓRIA DA EDUCAÇÃO, 3., 2004, Curitiba. Anais... Curitiba: 2004. Disponível em <http://www.sbhe.org.br/novo/congressos/cbhe3/Documentos/Coord/ Eixo5/478.pdf>. Acesso em: 29 dez. 2017.

FONSECA, N. Alda Lodi, entre Belo Horizonte e Nova Iorque: um estudo sobre formação e atuação docentes 1912-1932. 2010. Dissertação (Mestrado em Educação) - Faculdade de Educação, Universidade Federal de Minas Gerais, Belo Horizonte, 2010.

GONDRA, J. G. Apresentação - Dossiê: viagens de educadores, circulação e produção de modelos pedagógicos. $R B H E$, n. 22, jan./abr. 2010.

GONDRA, J. G.; SCHUELER, A. Educação, poder e sociedade no Império brasileiro. São Paulo: Cortez, 2008.

INTERNATIONAL INSTITUTE. Courses for students and teachers from foreign lands. Rockefeller Archives. International Education Board. RG 1010. Series 1. Box 19. Folder 275. 1923.

KATZ, E. Grace Hoadley Dodge: Women and the Emerging Metropolis, 1856-1914. 1980. Dissertation (Doctor of Philosophy, Ph. D.) - New York University, New York, 1980.

MACEDO, R. de B. do R. O Instituto de Pesquisas Educacionais do Distrito Federal nos anos de 1930. 2013. Tese (Doutorado em Educação) - Escola de Educação e Humanidades, Pontifícia Universidade Católica do Rio de Janeiro, Rio de Janeiro, 2013.

MACIEL, F. Lúcia Casasanta e o método global de contos: uma história da alfabetização em Minas Gerais. 2001. Tese (Doutorado em Educação) - Faculdade de Educação, Universidade Federal de Minas Gerais, Belo Horizonte, 2001. 
MINAS no collegio de professores da universidade de Columbia. O Jornal, Rio de Janeiro, edição 03151, p. 1, 02 mar. 1929.

PEIXOTO, A. M. C. Uma nova era na escola mineira: a reforma de Francisco Campos e Mário Casasanta (1927-1928). In: LEAL, M. C.; PIMENTEL, M. A. História e memória da Escola Nova. São Paulo: Loyola, 2003.

PINTO, K. Práticas de ensino, experimentação e pesquisa: a escola primária do IERJ na década de 1930. In: CONGRESSO BRASILEIRO DE HISTÓRIA DA EDUCAÇÃO, 3., 2004, Curitiba. Anais... Curitiba: 2004. Disponível em: <http://www.sbhe.org.br/ novo/congressos/cbhe3/Documentos/Individ/Eixo5/335.pdf> . Acesso em: 20 dez. 2017.

RUSSELL, J. E. The organization and administration of Teachers College. Organization of Teachers College. Teachers College Record, New York, v. 1, n. 1, p. 39-41, 1900a.

RUSSELL, J. E. The organization and administration of Teachers College. Courses of study in Teachers College. Teachers College Record, New York, v. 1, n. 1, p. 46-51, 1900 b.

SCHMUCK, P. Women school employees in the United States. In: SCHMUCK, P. (Org.). Women Educators: Employees of School in Western Countries. Albany, NY: State University of New York, 1987.

STROBER, M. H.; TYACK, D. Why Do Women Teach and Men Manage? A Report on Research on Schools. Signs, v. 5, n. 3, p. 494-503, Spring, 1980.

THOMAS, S. J. “Woman's Sphere” and Institutional Structure: Teachers College, Columbia University's Two School System, 1913-1933. 1986. Dissertation (Doctor of Education) - Teachers College, Columbia University, New York, 1986.

TOEPFER, K. H. James Earl Russell and The Rise of Teachers College: 1897-1915. 1966. Dissertation (Doctor of Philosophy, Ph. D.) - Teachers College, Columbia University, New York, 1966.

WENECK, B. C. The “Average Teacher” Need Not Apply: Women Educators at Teachers College, 1887-1927. 1996. Dissertation (Doctor of Philosophy, Ph. D.), Teachers College, Columbia University, New York, 1996.

YANNOULAS, S. C. Educar: una Profesión de Mujeres? La Feminización Del Normalismo y la Docencia en Brasil y Argentina 1870-1930. Revista Brasileira de Estudos Pedagógicos, Brasília, v. 74, n. 178, p. 713-738, set./dez. 1993.

Texto recebido em 27 de março de 2018. Texto aprovado em 18 de maio de 2018. 